\title{
Luces y sombras en la concepción europea de los Derechos Humanos
}

La Declaración de los Derechos Humanos es la conquista moral del siglo XX. La cuna de la idea de derechos humanos fundamentales innatos es Europa. Su fase embrional es la modernidad ilustrada. Comienzo mis reflexiones con un bosquejo histórico en el que recuerdo las distintas concepciones sobre el hombre que se han sucedido en Europa (1). Después, explico el núcleo de la idea de los Derechos Humanos (2). En la tercera parte (no incluida aqui) trato las estrategias de fundamentación más importantes en el concepto de los Derechos Humanos (3). Finalmente, discuto críticamente la concepción de los Derechos Humanos y sus consecuencias para sociedades no europeas (4).

\section{Concepciones históricas sobre el hombre en Europa}

Recordemos algunas concepciones del hombre que se han sucedido en Europa. Una parte de estos conceptos sobre el hombre contiene elementos de la idea actual de los Derechos Humanos, pero sólo elementos. Los derechos humanos son derechos personales, individuales, innatos, preestatales e inalienables con fuerza de validez universal. Este conjunto de propiedades va unido con un concepto de hombre en el que la capacidad de reflexión racional y la autonomía están en primer plano. Esta concepción ilustrada del hombre hà surgido bajo circunstancias históricas, políticas y económicas concretas. Si se intenta aplicar este concepto de los derechos humanos a culturas premodemas y no europeas, hay que tener en cuenta su origen a partir de la herencia de la modernidad occidental ilustrada. 


\subsection{Antigüedad}

El hombre antiguo vive enmarcado en un ambiente natural y social relativamente comprensible. Su aspiración se orienta hacia el equilibrio y a evitar los extremos. El cosmos y el estado se muestran con trazos orgánicos. Del mismo modo que cada cosa tiene su lugar natural, así también a cada ser humano se le asigna un lugar y una función en la sociedad. Este lugar se le asigna al ser humano desde el nacimiento. En la antigüedad griega y en el helenismo la imagen del mundo es cíclica. En ella, la idea del desarrollo y del progreso no tiene lugar, como tampoco el concepto moderno de autonomía. El Estado, como el cosmos, está articulado jerárquicamente. Los seres humanos son por naturaleza, desiguales -las mujeres tienen una posición más baja que los hombres, los esclavos una posición más baja que los ciudadanos libres - y esto a pesar de que concepciones iusnaturalistas tempranas (la sofística y la stoa) propagan la igualdad natural de los seres humanos.

\subsection{Edad Media cristiana}

La concepción cíclica del mundo de la antigüedad griega se sustituye en la Edad Media, influida por el cristianismo y el judaísmo por un concepto lineal. El ser humano se entiende como un ser temporal. La historia es un proceso teleológico. La historia no está hecha por los hombres, sino que su destino se encuentra enmarcado en el plan salvífico de Dios. Las virtudes humanas son la humildad, la piedad y el temor de Dios. Como producto del último día de la obra de Dios, el género humano es una parte de la naturaleza creada, y, por cierto, como coronación de la creación, lo que le da una dignidad especial. Por otra parte, está marcada la naturaleza humana por el pecado original. En la apreciación de la existencia humana la Edad Media no tiene una opinión única. El main stream deriva - apoyándose en Santo Tomás- la tarea del estado a partir de la idea del Adán caído, que sería la de disciplinar al ser humano para prepararlo al examen del juicio final. El Estado funge así como poena et remedium peccati. La vida humana no se orienta al bienestar sino a la salvación del alma. Algunos pensadores progresistas, como los jesuitas Bellarmino y Mariana, en el siglo XVI, hacen abstracción del pecado original y le dan al Estado la función de ser servidor de la Iglesia. Las dos fracciones convienen en que la vida espiritual tienen prioridad sobre la mundana. Por cada maltrato social sufrido por el hombre en la tierra, se puede esperar una compensación en la vida eterna. Esta esperanza frena toda aspiración a un ajuste social en la tierra. El concepto medieval del mundo es ampliamente incompatible con la idea de los derechos humanos, a pesar de la preparación de la idea de la dignidad humana. 


\subsection{Edad Moderna}

Con las ciencias naturales y matemáticas y su posibilidad de aplicación técnica se transforma de manera fundamental otra vez la relación hombre-naturaleza. El hombre se despoja de su temor frente a la naturaleza e interviene experimentalmente en ella para entenderla mejor y sobre todo para utilizarla en su favor. El principio formulado por Vico del verum factum caracteriza esta época. Es verdadero lo que el hombre puede hacer. Para entender la naturaleza, no solamente se la experimenta o se la comprende sino que se la reconstruye. En la medida en que la naturaleza es técnicamente reconstruible, el hombre se erige en su creador. Es más, él se pone en aquel sitio fuera de la naturaleza que la Edad Media le reservaba a Dios, pues su razón y su voluntad representan un desafío para las explicaciones de las ciencias naturales: como existencia libre y espiritual el hombre no aparece enraizado en la realidad material en la que rige la ley de la causalidad. Siguiendo a Kant, es el hombre ciudadano de dos mundos. No solamente frente al cosmos sino también frente al Estado tiene el hombre una posición doble - como ciudadano que tiene que obedecer las leyes, y como creador de las leyes. Kant consideró claramente esta posición doble al introducir el imperativo categórico. El hombre se convierte autónomamente en su propio legislador. El individuo se somete a la ley moral cuyo creador es él mismo. Él crea la ley cuya validez para sí él reconoce al mismo tiempo.

Entre el determinismo teológico de la Edad Media y el concepto moderno del homo faber y el self made man asume el hombre de la edad moderna una función de puente. Los humanistas subrayan la originalidad del individuo. El renacimiento, en especial, el italiano, es rico en personalidades extraordinarias. Los hombres son emprendedores pero son desiguales entre sí. Al mismo tiempo surge dentro del Renacimiento, en el medio protestante y especialmente en el calvinista, el paradigma del empresario que tiene que demostrarle al mundo que pertenece a los escogidos por Dios. El empresario es una nueva forma de benefactor -él promueve el bienestar propio y el de los demás- por eso está segura la legitimación delante de Dios desde un principio. Con la conexión del experimentador tecnológico y el espíritu emprendedor se pone el fundamento en la Edad Moderna temprana para el concepto de que los negocios que van bien son algo buenos porque ayudan a que aumente el bienestar de la sociedad.

En el mercantilismo del siglo XVI al siglo XVIII, la economía sirve a la conservación del Estado (absolutista). En sus primeros rasgos se dibuja la triada conceptual de progreso-desarrollo-aumento de bienestar. En el siglo XIX la economía pasa de ser una economía nacional a ser un medio 
de la maximización privada de lo productivo. El bienestar de las naciones (Adam Smith) ya no es la meta de la economía sino el bienestar individual. El individuo no está al servicio del aumento del bienestar nacional sino que el Estado asume la función de garantizarle a los ciudadanos la existencia que les hará posible a ellos aumentar su propio bienestar.

Este giro se produce por dos acontecimientos centrales para la idea de los derechos humanos: la Declaración de la Independencia norteamericana (1776) con la exigencia de tres derechos humanos - life, liberty and pursuit of happiness - y la Revolución Francesa de 1789, con sus consignas de libertad, igualdad y fraternidad, que operan hasta el siglo XX.

En la Edad Media y en la Edad Moderna temprana, los hombres se diferencian por la elección de la gracia divina. En el siglo XIX ocupa su lugar la competencia terrena en la que los hombres se diferencian en relación a su destino y su felicidad. Los hombres —así dice la teoríaentran en competencia como iguales. Sólo a partir del siglo XVIII resulta históricamente operativa la idea de los derechos humanos. "Los hombres son por naturaleza igualmente libres e independientes y poseen ciertos derechos innatos que son independientes de las condiciones jurídicas histórico concretas y constitucionales de los respectivos países", se dice en el Virginia Bill of Rights de junio de 1776. Casi dos mil años antes habían formulado los estoicos una concepción parecida que, sin embargo, no tuvo consecuencias políticas. ¿Por qué la diferencia?

La idea moderna de la autonomía tiene sus raíces en la experiencia de las clases altas (iglesia, nobleza, burguesía) que, en conexión con la Magna Charta Libertarum (1215) había iniciado en distintos países iniciativas exitosas contra el gobierno a fin de lograr una limitación del poder. Aunque aquí se trataba de asegurar los privilegios de unos pocos. La idea de la igualdad tiene entonces otras raíces. No viene tanto de la esfera política como de la económica: pasa su prueba de fuego como hermana gemela de la idea de la competencia.

La idea de los derechos humanos apenas podría, por tanto, ajustarse al concepto antiguo del hombre que tenía como virtudes supremas las virtudes de la sabiduría y de la serenidad, virtudes de contemplación y de la autolimitación. Tampoco podría ajustarse a la vida de la Edad Media, que tenía como virtudes supremas el estar bien con Dios y la humildad. Esta idea surge en un contexto completamente distinto, el de la exigencia de un estado civil y servidor de los intereses de sus ciudadanos. Esta exigencia parte de personas activas y autoresponsables que, como sujetos económicos, están en competencia y que han comprendido que la competencia es limpia sólo entre iguales. 


\section{La idea de los derechos humanos como conquista innovadora de la política moral moderna}

De manera muy resumida se puede bosquejar la diferencia entre la modernidad europea y las épocas premodernas de la siguiente manera:

En condiciones preilustradas dominan concepciones holísticas. La sociedad es más que la suma de sus partes. El individuo está en relación funcional u orgánica con el todo, pues fuera del contexto inicial no puede sobrevivir. De acuerdo con esto, está en una relación de servicio con la colectividad. En la modernidad los acentos se ponen en sentido contrario: la primera unidad social es el individuo. La colectividad no es nada más que la suma de sus miembros, una unión en la que entra por el motivo racional de que la pertenencia a una sociedad organizada corporativamente debe ser preferida a una vida en orgullosa autarquía. Para la realización del postulado de la igualdad resulta definitiva la idea de la competencia económica: mientras que para la cooperación entre orquesta, solista y dirigente), la igualdad de los "miembros del equipo" es inherente al concepto de la competencia limpia.

Bastan estas indicaciones para explicar ahora el concepto de los derechos humanos: un derecho humano es un derecho personal, individual, innato, preestatal e inalienable, con fuerza de validez universal. Los derechos humanos valen para cada persona por igual ¿Qué significa esto, más exactamente?

- El individuo está a salvo de tener que sacrificarse a favor de la colectividad o de una parte de ella, o de tener que someterse a ella. Los derechos humanos protegen a los individuos de la arrogancia de la sociedad y de los poderosos en ella, pues son individualistas.

- El campo de validez de los derechos humanos no se agota ni en una capa social o en un determinado sector profesional ni en una determinada etnia ni en el territorio de un Estado. Los derechos humanos le corresponden a cada persona como persona. Valen universalmente.

- Con el postulado de la igualdad original de todos los hombres queda sometida cualquier forma de desigualdad social a la necesidad de justificarse. Un derecho fundamental es derecho fundamental cuando vale: el hecho de que el derecho $R$ vale para la persona $P$, justifica la conclusión de que el mismo derecho $\mathrm{R}$ vale para todas las personas. Los derechos humanos son igualitarios.

- Los derechos humanos se relacionan con el "derecho natural", por donde el derecho natural hay que verlo como precediendo a todo derecho positivo. No depende por tanto de la buena voluntad del gobier- 
no ni cambia tampoco con un cambio de gobierno o de la forma de gobierno. La tarea del gobierno es, más bien, la de anclar los derechos humanos en la Constitución como derechos fundamentales y de realizarlos en el estado. Los derechos humanos son innatos y preestatales.

- Incluso cuando alguien no haga uso de un derecho que le corresponda por la Declaración de los Derechos Humanos, no puede delegar este derecho en otros o convertirlo en objeto de cambio. El derecho a asistir a una escuela pública no se puede cambiar por el de ser exonerado del servicio militar o por la disminución de los impuestos. El ciudadano está obligado a aceptar los derechos que le corresponden. Estos son inalienables.

A pesar de su pretensión universalista, el concepto igualitarista del hombre de la declaración de los derechos humanos es resultado de una determinada cultura en un determinado tiempo. Ilustremos brevemente esta tesis en base a una comparación con el hinduismo.

El criterio para el hinduismo es la pertenencia a una casta. El sistema indio de las castas no se compagina con la idea de la igualdad. De modo parecido a la sociedad jerárquicamente articulada de Platón, éste está ajustado a una concepción cíclica del mundo. Pero a diferencia de la antigüedad griega el alma humana está expuesta al ciclo mismo (o la rueda) de las reencarnaciones, hasta que llegue al Nirvana. Si el individuo renace innumerables veces entonces es comprensible que recorra varias posiciones sociales, desde la del pordiosero hasta la del rey, o también la del comerciante. La igualdad se da, a lo sumo, al interior de una casta, pero nunca entre todos los seres humanos. Apoyándose en la idea de la reencarnación, el sistema de castas representa un concepto de mundo que contrasta claramente con el igualitarismo europeo moderno.

La exigencia de la realización de los derechos humanos es un momento esencial de la declaración de los derechos humanos. Pues la suposición del universalismo no es real si la protección de estos derechos no se extiende a todos los hombres. Pero esto sólo se puede conseguir en un mundo en el que el reparto de los recursos no es un juego de sumas y de ceros sino en el que la economía crece, y por cierto de manera más rápida que la población. Con la economía crece también el bienestar y gracias al bienestar se hacen posibles la paz y la libertad. Sólo sobre este telón de fondo se permite implementar la declaración de los derechos humanos. El concepto de mundo de $1948-\mathrm{y}$ el de los años 50' y 60' es respectivamente optimista: la pobreza absoluta debe ser eliminada en pocas décadas y expandirse a todas las sociedades el régimen de los derechos humanos. 


\section{Problemas del concepto de derechos humanos}

Puesto que el deseo de la universalidad pertenece a la esencia del espíritu moderno europeo, quiero intentar, en esta última parte, superar el eurocentrismo. En ello voy a problematizar algunos aspectos del concepto de los derechos humanos.

Una observación previa: la relación del Occidente con países no occidentales es desde hace tiempo implícitamente contradictoria. Dos citas de Samuel Huntington lo comprueban: "Los pueblos y gobiernos de culturas no occidentales no son ya víctimas de la colonialización occidental sino que configuran juntamente en la historia". El Occidente se sirve de instituciones internacionales, del poder militar y de medios económicos para controlar el mundo, para que conservar el predominio occidental y sus intereses y para fomentar los valores económicos y políticos del occidente." El Secretario de Estado de Singapur, Kishore Mahbubani, habla, refiriéndose a la segunda cita, de la incapacidad de Occidente para reconocer la significación de las distintas culturas y advierte sobre el peligro de que la combinación de estas dos frases puede llevar a la catástrofe.

En la política de desarrollo de Occidente se manifiesta la misma ambivalencia. Por una parte, el concepto de ayuda de desarrollo suena como si tuviese una buena porción de altruismo. Y de hecho, el fortalecimiento de los derechos humanos es una meta de la ayuda del desarrollo. Por otra parte, la ayuda de desarrollo ha pasado de ser ayuda a la modernización a ser ayuda para la integración en el mercado mundial. En esta función cumple sin embargo un papel de fomentador de la expansión occidental.

\subsection{Competencia sin igualdad de oportunidades}

El sistema económico mundial no es un campo favorable al mejoramiento de la situación de los derechos humanos en algunos países. Las condiciones de competencia son muy desiguales. En relación con el producto social por habitante la diferencia internacional es de más de 500:1. Estamos muy lejos hoy de cumplir el postulado de la igualdad. Es evidente que un país tiene tanto mejores oportunidades de competencia cuanto mejor económicamente esté. Puede invertir más en la investigación, etc. En muchos países conduce la necesidad de mejorar tanto la capacidad de competencia como la situación de los derechos humanos a un conflicto de prioridades.

\subsection{Los derechos son más que los deberes}

Sobre los deberes que se corresponden más con los derechos humanos, la Declaración de los Derechos Humanos dice sólo el mínimo necesario. 
Es evidente que en una sociedad organizada bajo condiciones de prosperidad al individuo tiene más derechos que deberes. Por lo general, son irrenunciables el deber del servicio militar y el de pagar los impuestos. A través de los impuestos, el ciudadano se libera de todo un número de deberes. El Estado asume por su parte tareas delegando funciones en un personal formado específicamente para las mismas. Poder disponer de las prestaciones de un Estado de bienestar es casi como el privilegio de vivir en un paraíso terrenal. Este privilegio sólo tiene ventajas: Una psicológica y otra ecológica. Una quinta parte de la población mundial reclama para sí tres cuartos de la necesidad energética mundial. Esto no tiene nada que ver con la igualdad.

\subsection{Los derechos colectivos no son considerados}

La idea de los derechos humanos no considera suficientemente las formas de vida en sociedades premodernas. Estas sociedades son, por lo general, más comunitarias. 